\title{
Historical Timber Structures in Sri Lanka: A Review on Pekada, Kenimandala and Madol-kurupawa
}

\author{
C. Jayawardana, K. Peiris and S. Wijesinghe
}

\begin{abstract}
History of building constructions in Sri Lanka goes back to pre-Christian era. Among the many building types, historical records indicate the presence of timber made buildings since this early period. Many of these buildings are either totally destroyed by now or in ruined state. However, some building types in which timber has been extensively used as construction material and were constructed during medieval times are still in preserved order. Some elements in these buildings are alien to current construction methodologies. Studies on them in structural perspectives would enable to conjecture the early forms of Sri Lankan buildings as well as to provide some alternative structural designs. Study on two such elements, widely used in medieval timber buildings in Sri Lanka, constitutes the core theme of this paper.
\end{abstract}

Key words: Historical timber structures, Pekada, Kenimandala, Madol-kurupawa

\section{Introduction}

Timber has been used in the construction of the buildings, bridges, machinery, boats etc., since mankind first learn to fashion tools. Early civilizations mark distinctive types of timber structures ranging from simple 'teepees'of native North Americans to sophisticated modular buildings in China. Our own historical records note the existence of buildings like Lovamahapaya in Anuradhapura (1 ${ }^{\text {st }}$ c. B.C), of which the super structure is supposed to be of timber. Some other types of early constructions where timber would have been used are chethiyaghara (the rotunda type that sheltered smaller stupas), bodhighara (shrines enclosing Bo-trees) and vatadage (circular relic house). Neither their physical forms nor any records detailing the construction features available today, hence only conjectured models would be possible. However, some building types like Tempitavihara (the shrines on pillars), Devala (shrines dedicated to deities), ambalam (resting places for way-farers); mandapa (assembly places for administrative routines) of which physical remains are still available in relatively preserved state present standing examples for the early construction methods. Although copious research literature available on their religions and architectural significance, their structural engineering aspects have not been studied adequately. One such aspect would be the joinery between different structural members

\section{Timber joints - General}

In an assembled system, it is important to consider the interaction of elements in various configurations. This introduces the need of joints between elements and the various force transfer methods through them. It also involves consideration of the effects of one element on others to which it is connected. In present day engineering practices, these interactions are mainly tackled through mechanical fasteners or carpentry or glued joinery. In many cases carpentry joints are supplemented by mechanical fasteners in order to ensure the correct fit of the connection or to allow the transmission of additional forces. Whatever the type, these joints are rigid in nature and designed to with stand the inner forces and moments transferred from one member to the others.

Properties of any structural material would change with the passage of time. In the case of timber, this is highly relevant. As timber is hygroscopic, its moisture content affects almost every property, which are important in structural terms; strength, stiffness, durability, dimensional changes (shrinkage and swelling),

Eng. C. Jayawardana, B.ScEng(Hons) (Moratuwa), MTech, MA, MIET, MIE (Sri Lanka), C.Eng, Project Manager, BBES Ceylon Pvt. Ltd. Katunayaka.

Eng. K.Peiris, B.ScEng (Moratuwa), MPhil, MA, MIE (Sri Lanka), C.Eng, Research Fellow, National Engineering Research and Development Centre, Ekala.

Eng. S.Wijesinghe, B.ScEng, (Moratuwa) MIE (Sri Lanka), C.Eng, Deputy General Manager, Central Engineering Consultancy Bureau, Colombo. 
shape stability, etc. This dependability on the surrounding conditions (air humidity, rain water, capillary water present in wet walls, etc.,) presents a risk to the stability in timber structures. Further, timber is highly susceptible for biological degradation due to fungi, insects and bacteria, affecting the internal molecular structure. All these conditions make timber requires more judgment than other building materials. According to Blass et al.[1], this is one reason for avoiding timber in present day construction industry, despite its increasing role as an ecologically favorable building material.

Apart from these internal conditions, the external conditions like wind loads, settlements, thermal effects would also contribute to the structure's behavior. All these internal and external conditions might induce deformations of structural members, which in turn produce internal forces and moments. Due to rigidity provided by mechanical, carpentry and glued joints, these forces and moments are transferred from one member to another. Highlighting the disadvantages of rigidity in joinery, Gordon [2] notes, “..a certain amount of flexibility may enable the loads to be even out in a beneficial way. Although it is true that furniture does not very often get broken, quite a good way of attempting to do so is to sit on a chair, three of whose legs are on the carpet while the forth rests, hopefully, on the bare floor. With traditional furniture the load may be spread over all the four legs by the distortion of the tenoned joints; in modern factory-made chairs with 'efficient' glued joints, these joints may just break, after which the chair is difficult to repair in any satisfactory way."

When a rigid structural member is supported with minimum number of supports respect to the expected external loads, only external forces and moments on the structure will create loads and moments at the supports. Internal forces such as thermal or moisture expansion will not create loads or moments at supports. Also small positional changes of members will not create significant loads and moments at supports. Therefore if a large structure could be constructed by assembling small rigid parts (members) and if these rigid parts are supported as discussed above, development of stresses in members will be limited for those from external loads on the same member (some supports will act as external load transfers to some other members). Therefore if all the external loads (including weight) are removed it is ensured that all the stresses in the members will be zero. There could be localized stresses induced due to internal forces, but such stresses will not be propagated throughout the structure through supports. Also small positional changes in the supports of the structure, such as shrinkage and swelling, no significant stresses will be developed in the structural members.

It is in this background, the following sections are dedicated to consider the structural behavior of two joinery methods adopted in the medieval Sri Lankan timber constructions naming (i) pekada and (ii) madol-kurupapawa. kenimandala should be the assembly of rafters and madol-kurupawa and hence not forms an individual structural member by itself.

\section{Pekada: Pillar - Beam Interface}

Interface between pillars and beams are vitally important as they directly handle the load transfer to the ground. In many mediaeval timber buildings in Sri Lanka, this interface is formed through an arrangement called pekada. This is an intermediate structural element used in the connection between pillar tops and beams. Briefing its construction details, Coomaraswamy notes [3],"A separately carved capitol or bracket (pe-kadaya) almost invariably intervenes between the pillar and the beam which it is to carry. This bracket is made of two pieces, fitting together, and when these are crossed together, the four faced bracket is completed; the top of the pillar itself is morticed in to the bracket through the centre of the parts crossed." The position of pekada in the overall structure is illustrated in below figure 2 taking the Audience Hall at Kandy as a typical example.

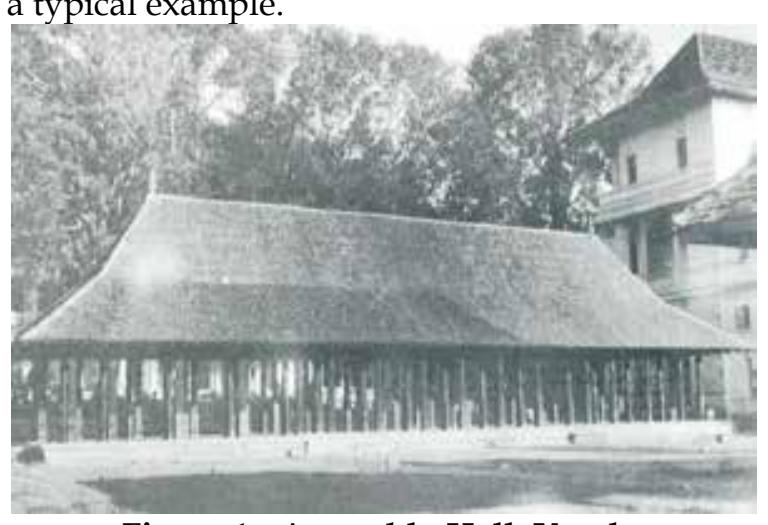

Figure 1 - Assembly Hall, Kandy 


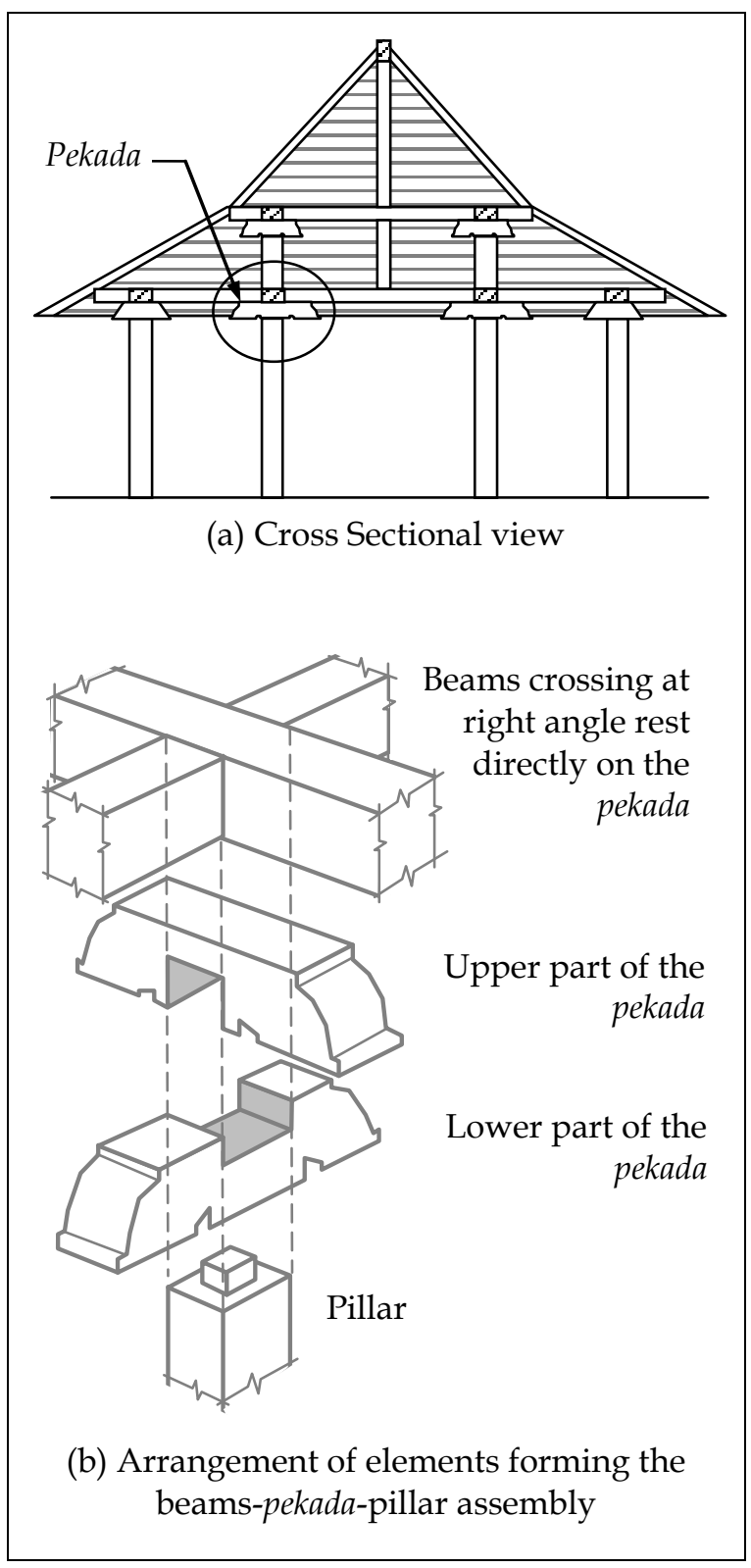

Figure 2 -Pillars, Beams and Pekada arrangement at Assembly Hall, Kandy

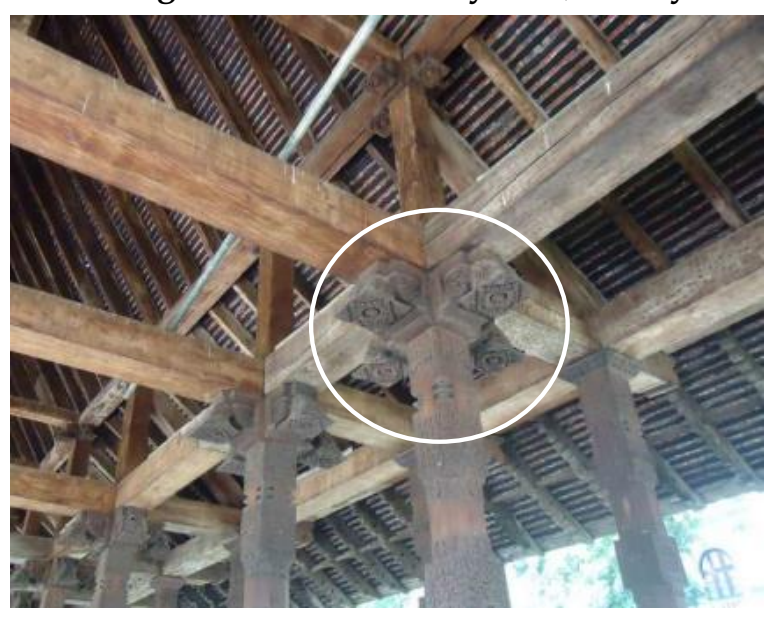

Figure 3 - Pekada at Assembly Hall, Kandy.
As discussed earlier, certain amount of flexibility would be beneficial in timber joinery. This would be possible by keeping beams on the pillar top in free standing manner connecting beams and pillars through mortice and tenon joints as illustrated in figures $4 \mathrm{a}$ and $4 \mathrm{~b}$ respectively.

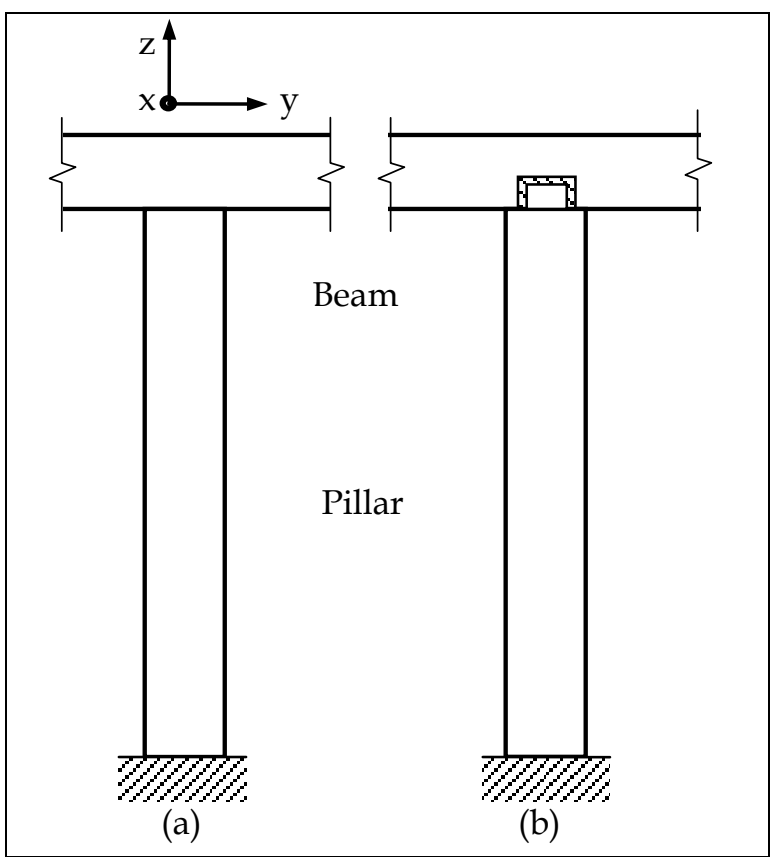

Figure 4 - Pillar and Beam structures

However, these measures cause some practical problems. In case (a) where beam rests directly on the pillar,

1. Positional stability is low.

2. High compressive stresses in $x-y$ plane adversely affect the stress conditions of beam at the contact area, which is also subjected to bending moments.

3. Inadequate provisions to handle lateral forces acting on the beam.

4. Such lateral forces inducing high bending moment at the pillar base and therefore the pillar should act as vertical cantilevers with fixed bases.

In case (b) where beam and pillar are connected through tenoned joint,

1. Local weakening of beam section.

2. Some amount of bending moment in the beam will be transferred to the pillar inducing more stresses in the pillar. This will apply even when there is no lateral force acting on beam.

These deficiencies were tackled in medieval constructions by introducing an interface element, pekada, between the beams and pillartop. Apart from addressing the above 
problems, pekada provides a means of minimum supports to the beam, thus achieving the structural characteristics as discussed in the section 2 above. The mechanism applicable in this arrangement is illustrated in figure 5. Accordingly, the beam only needs to support the horizontal force ' $\mathrm{P}$ ' and vertical load ' $R$ '. There is no need to have a support which prevents rotation (i.e transferring bending moments). This requirements well established by the arrangement of pekada. It provides the set of minimum supports for beam at 'A'. Also due to pekada the resistive moment needed at $\mathrm{B}$ (the point where the pillar is connected to the ground) will be less.

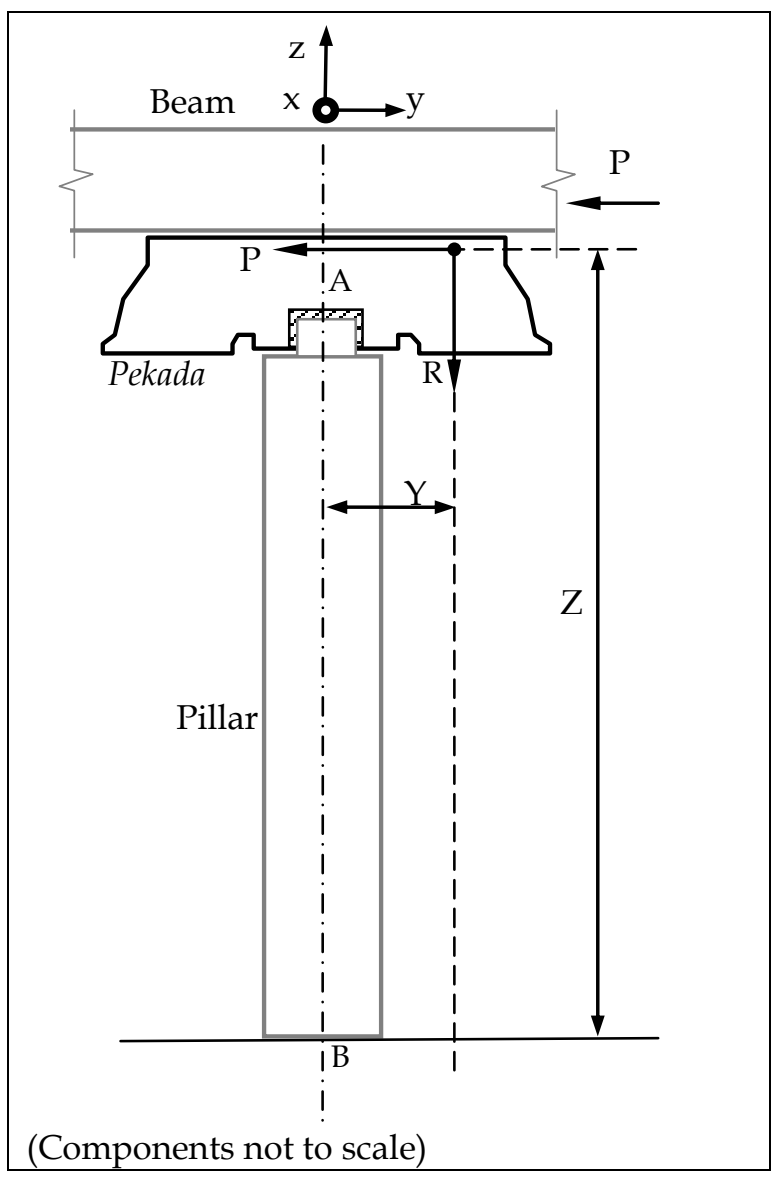

Figure 5 - Pekada, Force diagram

Say $M_{A}$ and $M_{B}$ are the maximum allowable bending moments at points $A$ and $B$. Considering the moments about $\mathrm{B}, \mathrm{M}_{\mathrm{B}}=\mathrm{PZ}-$ $R Y$, gives $P=\left(M_{B}+R Y\right) / Z$

When $\mathrm{M}_{\mathrm{A}} \geq \mathrm{RY}, \mathrm{P}_{\max }=\mathrm{M}_{\mathrm{B}}+\mathrm{RY} / \mathrm{Z}$. . .

When $\mathrm{M}_{\mathrm{A}}<\mathrm{RY}, \mathrm{P}_{\max }=\mathrm{M}_{\mathrm{B}}+\mathrm{M}_{\mathrm{A}} / \mathrm{Z}$

Therefore, bending moment due to $\mathrm{P}$ will be shared at points A and B. A pillar (with a pekada on top) carrying a load $\mathrm{R}$ will balance a lateral load $\mathrm{P}_{\max }$ given by equations (1) and (2) and it is clear that even if $\mathrm{M}_{\mathrm{B}}=0$ (case where no bending moment is transferred to base) bearable lateral load will not be zero.

This arrangement allows maintaining a certain amount of flexibility while keeping the structural stability. The conventional elements like bracing, which are normally employed to maintain the stability were alien to these medieval constructions. Local weakening would not occur as no material removal. No bending moments will be transferred between beam and pillar as they are not directly connected. The unique position of this arrangement when compared with modern structural design is evident, when WynneJones [4] made a comment in 1954 after inspecting Assembly Hall at Kandy for its structural stability, "It was found that there was no inherent principle design in the roof providing for resistance to any forces not vertical. There was a great deal of timber but no bracing that would deal with wind stress or any other disturbing forces.".It is pekada, which plays a vital role in handling these lateral forces. Pekada provides a method of transferring lateral as well as vertical loads of beams (especially when they crosses at right angles) to pillars without inducing high local stresses at the connection points. Further this arrangement prevents transferring of internal stresses due to thermal expansions, settlements, etc., from beams to pillars. Arrangements required at pillar base to handle the bending moments are also reduced by pekada.

\section{Madol-kurupawa: Rafters - Ridge plate Interface}

Roof is one of the prime requirements of any building. The way in which roofs are designed affects not only the appearance of the roof itself, but also the design of the other structural elements and the whole character of the building. The roof structures of the building types as discussed in previous section Chetiyaghara, bodhigara and Vatadage appear somewhat different to the modern pitch roof designs, as they are supposed to be either domical or conical in shape. Detailing the construction features of these, Paranavitana [5] notes, "Roof of a dage or cetiyaghara above the stupa was domical in shape and that it was constructed of rafters which must have been held together on the top by means of a circular boss - a feature which seems to be referred to 
under the name kannika in Pali and kenimandala in Sinhalese." As the remains of this roof style are not available at present, a detailed study would not be possible.

However, a similar structural arrangement is evident in the medieval buildings where four pitched type roofs have been provided. Rafters of the shorter sides are elbowed against the plate and were held fast at its pinnacle by a timber boss known as madol-kurupawa, which in turn attached to the end of the ridge plate. This arrangement is illustrated in figure 7, taking the Embekka devalaya at Udunuwara as a typical example. In this case, upper ends of twenty six rafters are held together using modol-kurupawa. As pekada provides an intermediate means of connection between the pillars and beams, modol-kurupawa provides similar means between rafters and ridge plate at shorter side of the pitched roof.

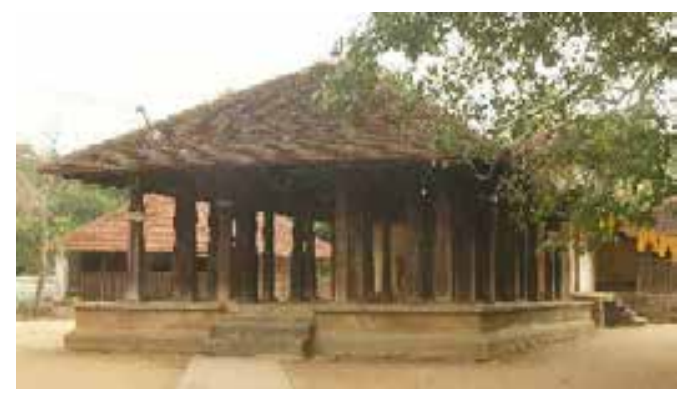

Figure 6 - Embekka Devalaya, Udunuwara

In this arrangement, no mechanical joinery has been provided and the stability achieved only through compression as shown in figure 8.

The joinery between the modol-kurupawa and end of the ridge plate is of mortice and tenon type with a clearance in between. Due to this clearance, madol-kurupawa has a slight freedom to rotate about a point like $O$. When rafter is placed on the modol-kurupawa, the initial contact would only at point B, but madolkurupawa would slightly rotate under the force $\mathrm{R}$ exerted by the rafter making another contact point A. Considering moment of madolkurupawa about point $\mathrm{O}, \mathrm{RY}=\mathrm{PZ}$ and as $\mathrm{Y}>>\mathrm{Z}$, $\mathrm{P}>>\mathrm{R}$. Compression of the ridge plate due to $\mathrm{P}$ is counter balanced by an equal and opposite force exerted at other end. Due to this arrangement, the forces exerted by rafters on ridge plate are converted to compressive forces, rather than introducing bending moments. This is favorable in structural means as timber is strong and stiff parallel to the grain, while shear strength and shear modulus are low. This marks an efficient design harnessing the natural properties of the material in achieving the structural requirement.

In this case rafters are supported at plate for horizontal and vertical loads (there is no moment transfer). Madol-kurupawa mainly handles the vertical loads. Now if the external loads (weight of roof and rafters) on rafters are removed it could be shown that forces at supports will be zero. Therefore rafters are supported by a set of minimum supports, having the structural behavior as discussed in section 2 above.

\section{Conclusion}

Remains of some medieval building types provide clues for the construction features of ancient timber buildings in Sri Lanka. Analysis of two structural elements of these buildings, namely pekada and modol-kurupawa was the core subject of this paper. These two elements were used in the assembly between pillars to beam and rafters to ridge plate respectively.

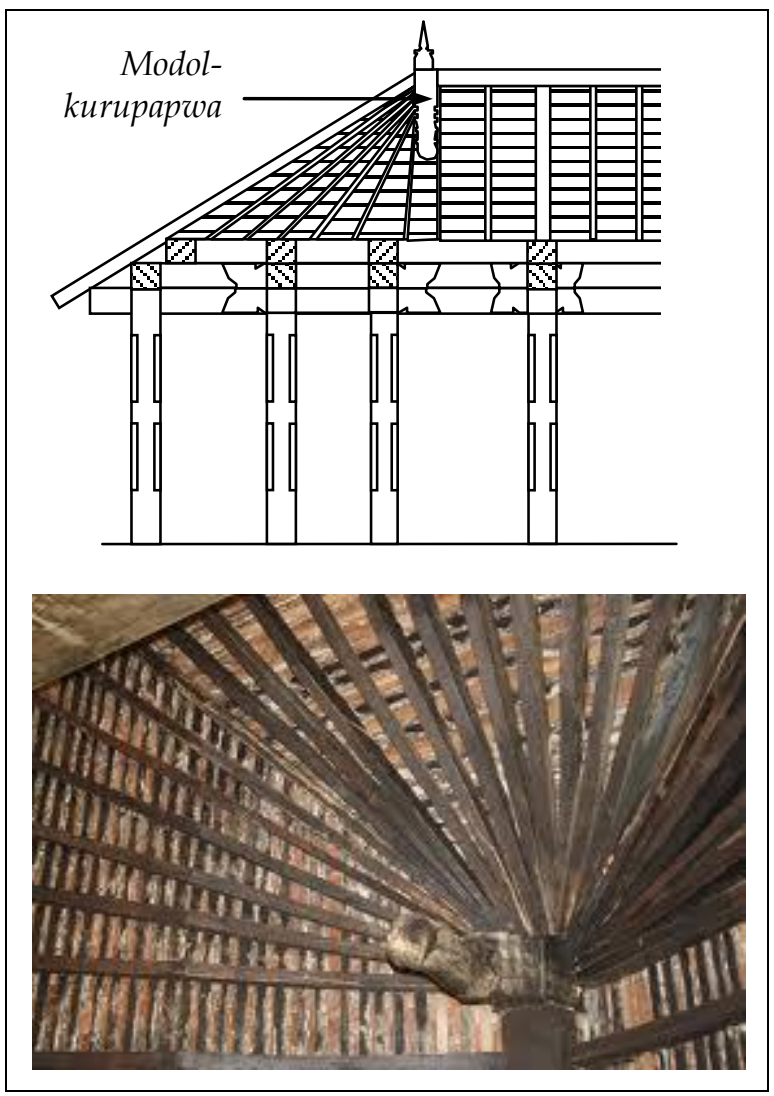

Figure 7-Rafters and ridge plate arrangement at Embekka Devalaya, Udunuwara 


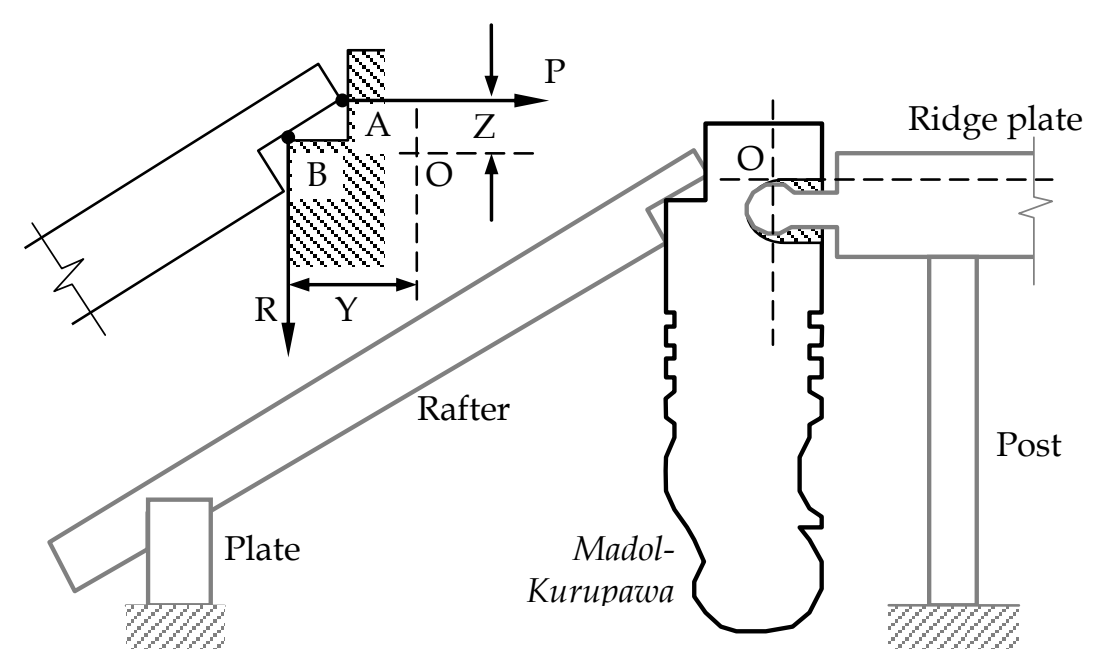

Figure 8 - Madol-kurupawa, Assembly between rafters and ridge-plate

None of them could be categorized in to the standard mechanical, carpentry of glued connections as interpreted in modern timber engineering. No mechanical fasteners were used in forming these connections. The weight and the friction of the members play a vital role in maintaining stability and individual members forming the assembly are provided with a certain degree of freedom for movements. The stress formation and the transfer of moments under the internal and external conditions would be minimal. Forces exerted on a certain member from other members have been formed to compressive forces, hence no need to design for tensile stresses.

One reason for minimal usage of timber in construction industry today is the varying degree of its material properties over a time period. This makes its structural behavior unpredictable and the modern mechanical and carpentry joints do not address such unpredictability. But, indigenous design criteria blended the natural properties of timber with the structural stability and sustainability by incorporating a degree of flexibility in connections by employing elements like pekada, and madol-kurupawa.

\section{References}

1. Blass, H. J., Anne, P., Choo, B. S., Görlacher, R., Griffith, D. R., Hilson, B. O., Racher, P., Stek, G., Timber Engineering, STEP 2, Design-Details and Structural Systems, Centrum Hout, The Netherlands, 1995, p.E2/1

2. Gordon, J. E., Structures, Penguin Books, 1984, p.134

3. Coomaraswamy, A., Mediaeval Sinhalese Art, 3rd ed., Pantheon Books Inc., New York, 1979, p.130

4. Wynne-Jones, T. N., The Independent Hall Freedom Sq., Colombo and Some Notes on Examples of the Solution of the Problem involved in the Structural Design of the Roof of the Audience Hall type Buildings, Annual Transaction, The Institution of Engineers, Ceylon, 1954, pp.25-40

5. Paranavitana, S., The Stupa in Ceylon, Memoirs of the Archeological Survey of Ceylon, Volume V, Colombo Museum, 1988, p. 88 